\title{
Pandemia de COVID-19 en el Perú: ¿Qué hicimos y qué pudimos hacer mejor?
}

\section{COVID-19 pandemic in Peru: What did we do and what could we do better?}

\author{
Sonia Indacochea-Cáceda'
}

\begin{abstract}
El objetivo de este editorial es mirar atrás para no volver a cometer los mismos errores a puertas de una segunda ola que ya está azotando a varios países de manera dramática. Un poco de historia. En diciembre de 2019 fueron reportados en Wuhan, China, una serie de casos con una enfermedad nueva caracterizada por neumonía e insuficiencia respiratoria, con alta letalidad. Se encontraron semejanzas con las epidemias previas de coronavirus del síndrome respiratorio agudo severo (SARS-CoV) producida en 2003 y del síndrome respiratorio del Medio Oriente (MERS) ocurrida en 2012. Se aisló el virus causante, perteneciente a la familia Coronarividae, se le denominó coronavirus 2 del síndrome respiratorio agudo grave (SARS-CoV-2) y a la enfermedad COVID-19.

El 11 de marzo, la COVID-19 fue declarada pandemia en una rueda de prensa mundial por Tedros Adhanom Ghebreyesus, director general de la Organización Mundial de la Salud (OMS), quizá con algún tiempo de retraso, ante el avance de la enfermedad en los países de Europa, Asia y América, con las siguientes recomendaciones: ${ }^{1}$

Desde entonces, hasta el día de hoy, se registraron 66818 756 casos en el mundo y 1533018 fallecidos según el Centro Johns Hopkins de Ciencia e Ingeniería de Sistemas. En nuestro país, el primer caso fue diagnosticado el 6 de marzo y, según la misma fuente, registra 972688 casos y 36231 fallecidos. Tenemos la más alta tasa de letalidad del mundo. Si revisamos los consejos de la OMS, los más de nueve meses de pandemia han demostrado que tenemos un sistema de salud precario en infraestructura, equipamiento, recursos humanos y, sobre todo, fragmentado.
\end{abstract}

I Presidenta de la Sociedad Peruana de Medicina Interna. Médico Internista. Jefa del Servicio de Medicina Interna, Hospital Nacional EsSalud Edgardo Rebagliati Martins. Docente de la Facultad de Medicina de la Universidad Ricardo Palma. Instituto de Investigación en Ciencias Biomédicas URP, Lima, Perú.
Indacochea-Cáceda, S. Pandemia de COVID-I9 en el Perú: ¿Qué hicimos y qué pudimos hacer mejor?. Rev Soc Peru Med Interna. 2020;33(4): I32-134.

https://doi.org/10.36393/spmi.v33i4.557

Por tema de disponibilidad para compra, el Perú utilizó las pruebas serológicas como pruebas diagnósticas, lo cual ha producido que las estadísticas del COVID-19 resulten controversiales pues incluyen pacientes positivos tanto a pruebas serológicas como moleculares. La recomendación actual es que las pruebas serológicas no deben utilizarse para el diagnóstico de la infección aguda por SARS-CoV-2, ni tampoco deben usarse para determinar si una persona es inmune a la infección. El gold-standard para el diagnóstico es la prueba de la reacción en cadena de polimerasa de transcriptasa reversa (rT-PCR). ${ }^{2}$ De esta manera, reconocemos el esfuerzo inicial del MINSA por incentivar su uso como prueba diagnóstica, debiendo abandonar dicho uso ahora y, obviamente, la compra de dichas pruebas, salvo para fines de estudios epidemiológicos.

El Ministerio de Salud (MINSA) es el ente rector y emitió numerosas directivas en este tiempo de pandemia ${ }^{3-11}$, cuya implementación en un sistema de salud dividido parece haber sido una tarea difícil. Queda avanzar en el cumplimiento de estas normativas y actualizarlas de acuerdo con la evidencia científica.

Cada subsector del sistema de salud tomó decisiones diferentes, así el paquete de medicamentos repartidos por EsSalud a los pacientes ambulatorios consideraba adicionar azitromicina que no era considerada como tratamiento por el MINSA. Por su parte, éste incluyó tratamientos con hidroxicloroquina e ivermectina para casos leves con factores de riesgo. Poco a poco, la literatura desestimó con ensayos clínicos controlados el uso de la primera droga, primero en hospitalizados y luego en ambulatorios. ${ }^{12,13}$ y aún no son publicados los resultados de estudios serios con la segunda. La azitromicina tampoco tuvo sustento en la evidencia científica. L a p osibilidad d e d isponer de estos medicamentos creó la falsa seguridad que hizo que las personas se confiaran y $\mathrm{n}$ or espetaran 1 as medidas 


\begin{tabular}{|l|l|}
\hline Tabla I. Consejos de la OMS a todos los países \\
\hline Petición a todos los países para activar e incrementar mecanismos de respuesta a la emergencia \\
\hline Presente & Futuro \\
\hline No estábamos preparados. & Innovar y aprender. \\
\hline Detectar, aislar, test, tratar cada caso y trazar sus contactos. & Detectar, proteger y tratar. \\
\hline Adecuar los hospitales. & Dotar, adecuar y preparar los hospitales. \\
\hline Proteger y entrenar a los trabajdores de la salud. & Preparar y estar listos. \\
\hline Comunicar a la población los riegos y cómo se pueden autoproteger. & Dotar, adecuar y preparar a la Atención Primaria. \\
\hline Reducir la transmisión. & Prteger y entrenar a los trabajadores de la salud. \\
\hline Cuidar a los demás porque los necesitamos. & Cuidar a los deás porque los necesitamos. \\
\hline Innovar y aprender. & Educar y entrenar a la ploblación. \\
\hline
\end{tabular}

de prevención. Por otra parte, el reparto de bolsitas de medicamentos fue utilizado con fines políticos por autoridades y alcaldes.

En el país se usaron de manera extendida hidroxicloroquina, azitromicina e ivermectina, basados en la experiencia personal, muchas veces en controversia con la evidencia científica. Esto fue modificado acertadamente por el MINSA ${ }^{3}$ para los dos primeros fármacos, quedando pendiente el caso de la ivermectina. Prescribir medicamentos sin evidencia científica tiene implicancias éticas, sobre todo si el paciente desconoce la eficacia, los posibles efectos adversos y los costos de esa prescripción médica. Queda en manos de los médicos la decisión de su prescripción de acuerdo con los resultados de los ensayos clínicos a la vez que van enriqueciendo su propia experiencia.

Se usaron corticoides en fases tempranas de la enfermedad, durante la replicación viral. En el estudio Recovery ${ }^{13}$, los pacientes hospitalizados con COVID-19 se beneficiaron con el uso de dexametasona $6 \mathrm{mg}$ /día por 10 días, llevando a una menor mortalidad a los 28 días entre los que estaban recibiendo ventilación mecánica invasiva u oxígeno. Nos equivocamos en sugerir el uso de pulsos de metilprednisolona ${ }^{9}$, con el riesgo de ocasionar infecciones bacterianas sobreagregadas. Con el remdesivir se ha encontrado utilidad para pacientes hospitalizados que requieren oxígeno, acortando el tiempo de estancia hospitalaria. No se recomienda el uso de lopinavir/ritonavir. Con tocilizumab no se alcanzó los objetivos esperados y bamlanivimab se usa solo en el contexto de ensayos clínicos específicos. ${ }^{2}$

Efectivamente, no estábamos preparados. Miramos a los hospitalesde nivel III, en los primeros meses de pandemia, haciendo esfuerzos por mejorar la oferta de camas hospitalarias y de las unidades de cuidados intensivos (UCI), que aún no son suficientes. Hemos visto morir a pacientes esperando la posibilidad de acceder a un ventilador y una cama de UCI, quizá esta es la experiencia más dolorosa que hemos tenido los médicos, además de ver partir a cerca de 250 de nuestros colegas. Hoy tenemos que mirar hacia los establecimientos del primer nivel de atención, muchos aún están cerrados y sin personal suficiente para abrirlos. La finalidad sería hacer el diagnóstico y aislamiento precoz de los casos nuevos en sus domicilios, así como el rastreo de los contactos -eficaz medio de controlar la epidemia- que deberá ser implementado a nivel nacional a la brevedad posible, ya que los casos han disminuido y el virus nos está dando una tregua que debemos aprovechar.

Un tema importante es el relacionado a los recursos humanos. Reconocemos el esfuerzo por la protección y el cuidado del personal de salud ${ }^{11}$; sin embargo, creemos que no fue acertado normar que el personal de salud mayor de 60 años dejara de trabajar, aun no teniendo comorbilidades. Luego una modificación dispensando solo a los mayores de 65 años. En la actualidad, los profesionales de la salud dispensados, que pueden alcanzar al 50\% del personal de un establecimiento no se han reincorporado a trabajar y los que quedaron trabajando activamente, luego de nueve meses de lucha contra la pandemia, están con agotamiento físico y emocional. Ya es hora de regresar a los establecimientos de salud a reforzar los equipos de trabajo y de optimizar la normativa para que se haga efectivo.

Un tema pendiente es el control de aerosoles durante los procedimientos que los generan en los ambientes hospitalarios. ${ }^{2}$ Los aerosoles son partículas muy pequeñas de $<5 \mu$ y es fundamental que se adopte toda medida para la prevención del contagio del personal de salud.

En medio de todo este escenario, hubo héroes a los que expreso nuestra gratitud y rendimos homenaje: el personal asistencial de salud de la primera línea de batalla, muchos enfermaron, volvieron a sus labores y siguen trabajando agotados, fieles a su vocación de servicio. Algunos ya no están entre nosotros. Hay que destacar el rol de nuestros jóvenes médicos, especialmente de los médicos residentes en esta pandemia.

Vimos muestras de solidaridad en la sociedad, como el esfuerzo del sacerdote Raymundo Portillo, en Iquitos, por conseguir una planta de oxígeno y el empresario Mario Romero Pérez, llamado el "ángel del oxígeno", por 
mantener precios accesibles para la población necesitada. El camino aún es largo, nos necesitamos unos a otros para seguir luchando en la misma trinchera: autoridades, políticos, profesionales de la salud y ciudadanos, por el camino del dialogo y del servicio generoso, sosteniendo este precario sistema de salud, proporcionando una atención médica de calidad a nuestros pacientes, esperando que en los próximos meses la población peruana sea vacunada y este aciago tiempo pase.

\section{REFERENCIAS BIBLIOGRÁFICAS}

I. Serrano-Cumplido A, Antón-Eguía Ortega PB, Ruiz García A, Olmo Quintana V, Segura Fragoso A, Barquilla García A, Morán Bayón Á. COVID-19. La historia se repite y seguimos tropezando con la misma piedra [COVID-19. History repeats itself and we keep stumbling on the same stone]. Semergen. 2020 Aug;46 (Suppl I):4854.

2. COVID-19 Treatment Guidelines Panel. Coronavirus Disease 2019 (COVID-19) Treatment Guidelines. National Institutes of Health. URL disponible en: https://www.covid I9treatmentguidelines.nih. gov/RM N 375 -2020 MINSA. Documento técnico: Manejo ambulatorio de personas afectadas por COVID-19 en el Perú. URL disponible en: https:/www.gob.pe/institucion/minsa/normaslegales/673382-375-2020-minsa

3. $R M N^{\circ} 928-2020$ MINSA. Documento Técnico: Plan de preparación y respuesta ante posible segunda ola epidémica por COVID-19 en el Perú. URL disponible en: https://cdn.www.gob.pe/uploads/ document/file/ I437467/RM\%20N\%C2\%B0928-2020-MINSA.pdf.

4. RM N 848 -2020 MINSA. Documento Técnico: Plan Nacional de vacunación contra el COVID 19. URL disponible en: https://www. gob.pe/institucion/minsa/normas-legales//293043-848-2020-minsa
5. RM N 5 I 3 -2020 MINSA. Documento Técnico: Gestión de camas hospitalarias para la hospitalización de pacientes con COVID-19 y camas $\mathrm{UCl}$ para pacientes o sospechosos confirmados con COVID-I9 en las IPRESS públicas, privadas y mixtas. URL disponible en:https://cdn.www.gob.pe/uploads/document/file//032747/ RM_5 I 3-2020-MINSA.pdf

6. RM N ${ }^{\circ} 456-2020$ MINSA. Documento Técnico: NT de Salud para el uso de equipos de protección personal por los trabajadores de las instituciones prestadoras de Servicios de Salud. URL disponible en: https://cdn.www.gob.pe/uploads/document/file/931760/RM_ 456-2020-MINSA.PDF

7. RM N 254 -2020 MINSA. Documento Técnico: Manejo de personas afectadas por COVID-19 en áreas de atención crítica. URL disponible en: https://cdn.www.gob.pe/uploads/document/file/ 686689/R.M._N_254-2020-MINSA.PDF

8. RM N ${ }^{\circ} 240-2020$ MINSA. Documento Técnico: Modificaciones al tratamiento del Documento Técnico N| 193-2020 MINSA. URL disponible en:https://cdn.www.gob.pe/uploads/document/file/ 66836I/RM_240-2020-MINSA.PDF

9. RM N $N^{\circ} 193-2020$ MINSA. Documento Técnico: Prevención, Diagnóstico y Tratamiento de personas afectadas por COVID- 19 en el Perú. URL disponible en: https://cdn.www.gob.pe/uploads/ document/file/582549/RM 193-2020-MINSA.PDF

10. RM N 448 - 2020 MINSA. Documento Técnico: Lineamientos para la vigilancia y control de la salud de los trabajadores con riesgo a exposición a COVID-19. URL disponible en: https://cdn.www.gob. pe/uploads/document/file/903763/RM_448-2020-MINSA.pdf

II. Alerta de actualización 3: hidroxicloroquina o cloroquina para el tratamiento o profilaxis de COVID-19. Annals Int Med. Dec 0I, 2020. URL disponible en:https://doi.org// 0.7326/L20-I 257

12. Adrian V. Hernandez; Yuani M. Roman; Vinay Pasupuleti; Joshuan J. Barboza and C. MichaelWhite. Hydroxychloroquine or Chloroquine for treatment or prophylaxis of COVID-19. A living systematic review. Ann Intern Med. 2020; 173:287-296. doi: I0.7326/M20-2496.

13. El grupo colaborativo RECOVERY. Dexametasona en pacientes hospitalizados con COVID-19. Informe preliminar. 17 de julio de 2020. DOI: I0.1056 / NEJMoa202I436 